\title{
Difficult tracheal intubation and post- extubation airway stenosis in an 11-month- old patient with unrecognized subglottic stenosis: a case report
}

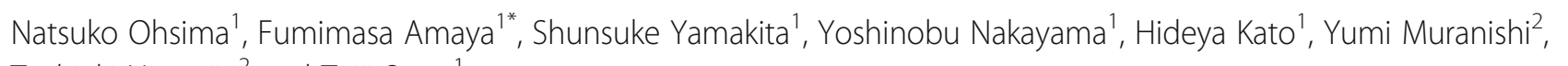
Toshiaki Numajiri $^{2}$ and Teiji Sawa'

\begin{abstract}
Background: Subglottic stenosis can lead to life-threatening difficult tracheal intubation during general anesthesia. We report a case of difficult tracheal intubation in an 11-month-old female who had unrecognized subglottic stenosis.

Case presentation: The patient was scheduled for elective correction of a right accessory auricle. She was suspected of having first and second branchial arch syndrome. Preoperative physical examination was normal. Anesthesia was induced uneventfully using sevoflurane. It was not possible to pass size 4.0, 3.5, or 3.0 cuffed endotracheal tubes due to an advanced subglottic lesion. Subsequent successful intubation was achieved using a 3.0 uncuffed tube. Stridor was audible after extubation, and the patient required several days' treatment with dexamethasone to address respiratory distress.
\end{abstract}

Conclusions: We encountered unrecognized subglottic stenosis that led to difficult tracheal intubation and post-extubation airway stenosis.

\section{Background}

Subglottic stenosis is a risk factor for difficult airway management under general anesthesia. However, this may be unrecognized in patients and only present when tracheal intubation is attempted. We report a case of unrecognized subglottic stenosis in a patient scheduled for elective surgery that led to difficult tracheal intubation and post-extubation airway stenosis that continued for several days. Written, informed consent from the patient's parent was obtained before publication of the case report and is available on editors' request.

\section{Case presentation}

An 11-month-old female was scheduled for elective correction of a right accessory auricle. Her body weight was $7.1 \mathrm{~kg}$ and height was $69.8 \mathrm{~cm}$. The patient was born at 38 weeks, with a birth weight of $2796 \mathrm{~g}$ and a

\footnotetext{
* Correspondence: ama@koto.kpu-m.ac.jp

'Department of Anesthesiology, Kyoto Prefectural University of Medicine,

Kajii-cho 465 Kamigyo-Ku, Kyoto 604-0096, Japan

Full list of author information is available at the end of the article
}

normal Apgar score. At 4 months of age, she was suspected of having first and second branchial arch syndrome because of paralysis of the left marginal mandibular branch of the facial nerve, as well as hypotrophy of the left side of the mandible, external auditory canal, and tympanum. Preoperative investigations including laboratory tests, chest X-ray, and electrocardiograph were normal. Figure 1 demonstrates her preoperative chest X-ray. Preoperative examination of her airway and respiratory system demonstrated normal mouth opening, no apparent differences between the extremities of the mandible, and normal respiratory sounds on auscultation. We could not detect any signs predictive of difficult airway management such as a short neck, reduced immobility, or small-sized jaw.

Anesthesia was induced with inhalation of $67 \%$ nitrous oxide, 33\% oxygen, and sevoflurane. Muscle paralysis was achieved by administration of $20 \mathrm{mg}$ rocuronium after obtaining intravenous access. The glottic view on direct laryngoscopy using a Robertshaw blade was Cormack-Lehane Grade I. Tracheal intubation was 


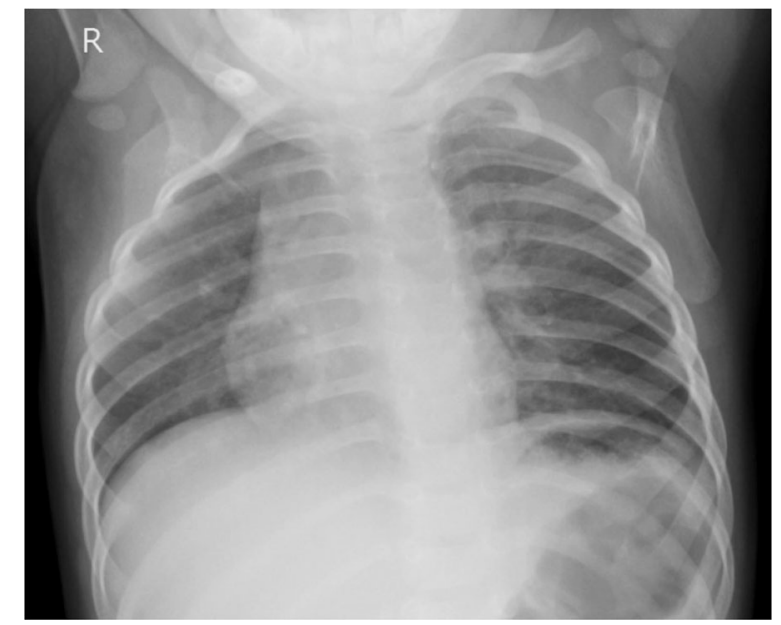

Fig. 1 Chest $X$-ray images taken prior to the surgery

attempted with a size 4.0 cuffed spiral tube; the size of the tube selected was based on her age. This was unable to be advanced into the subglottic region. Bag-mask ventilation was maintained during the procedure. Attempts to intubate with smaller sized tubes, up to size 3.0 cuffed, were unsuccessful. Intubation was subsequently successful using a size 3.0 uncuffed tube. No air leak around the tube was detected when airway pressures were below $30 \mathrm{~cm} \mathrm{H}_{2} \mathrm{O}$. In total, tracheal intubation was attempted four times. The first attempt was by an anesthesia resident and following attempts were by a JSA board certified anesthesiologist. The duration from induction to intubation was 28 min.

Anesthesia was maintained with inhalation of air, oxygen, and sevoflurane. The surgery proceeded uneventfully. The duration of surgery was $19 \mathrm{~min}$. Residual neuromuscular blockade was reversed with $50 \mathrm{mg}$ of sugammadex. The patient was extubated awake. After extubation, pulse oximetry revealed an oxygen saturation of $97-98 \%$ on room air, and stridor was not audible when she was not agitated. Fiberoptic laryngoscopic examination was performed by the otorhinolaryngologist $4 \mathrm{~h}$ after the extubation. Swelling or redness of the vocal cords and arytenoids could not be detected. Dexamethasone $(3.3 \mathrm{mg})$ was administered intravenously.

On postoperative day (POD) 2, stridor was audible at rest, and the patient appeared fatigued. Her $\mathrm{SpO}_{2}$ decreased from $93-95 \%$ on room air. Oxygen was commenced at $1 \mathrm{~L} / \mathrm{min}$ via nasal cannula. Fiberoptic laryngoscopic examination by the same otorhinolaryngologist revealed swelling and redness of the subglottic region of the trachea. Her respiratory condition improved after treatment with $3.3 \mathrm{mg}$ of intravenous dexamethasone and nebulized epinephrine.

Computed tomography (CT) images of the neck showed narrowing of the subglottic portion of the trachea (Fig. 2). The diameter at the narrowest level was calculated as $2.8 \mathrm{~mm}$. Daily treatment with $3.3 \mathrm{mg}$ of dexamethasone was continued up to POD 4. Her respiratory condition continued to improve, and oxygen treatment was discontinued on POD 5. A CT scan of the neck done on POD 7 demonstrated that subglottic stenosis at the level of the cricoid cartilage was still present (Fig. 3), with the diameter at the narrowest level being $3.6 \mathrm{~mm}$. After confirming that the patient's respiratory condition had not worsened after discontinuing dexamethasone, the patient was discharged from the hospital on POD 7.

\section{Discussion}

Subglottic stenosis can result in difficult tracheal intubation at induction of anesthesia [1-4]. Subglottic stenosis may be either congenital or acquired [5]. The case presented here was considered as being congenital,
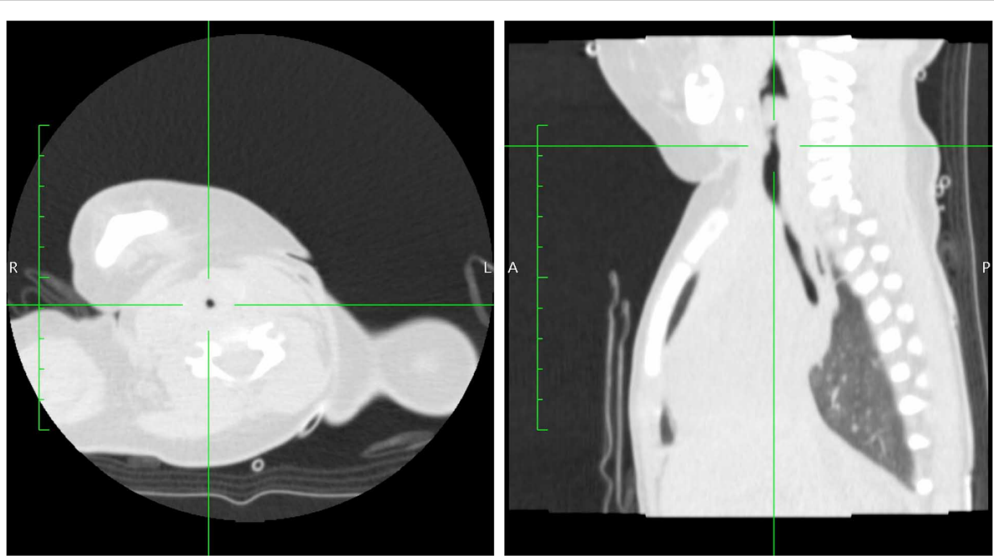

Fig. 2 Neck CT images taken at POD 2. Subglottic stenosis of the trachea was detected. Tracheal diameter at the narrowest level was calculated as $3.2 \mathrm{~mm}$. Left, transverse image of the neck. Right, sagittal image of the neck 

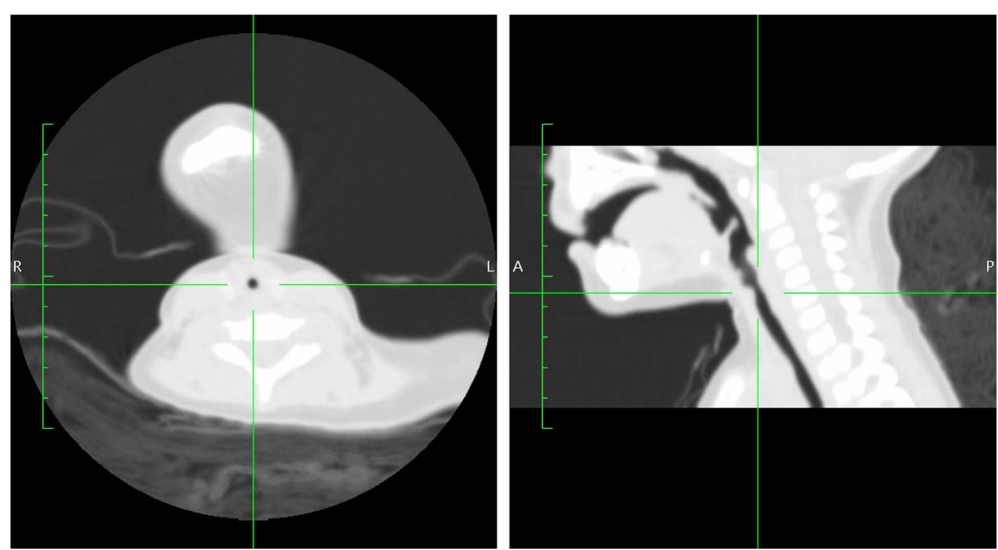

Fig. 3 Neck CT images taken at POD 7. Tracheal stenosis was improved but still existed at the subglottic level. The sagittal plane image demonstrates the process of the anterior wall of the trachea (arrow in the right panel). Left, transverse image of the neck. Right, sagittal image of the neck

as the patient had not received previous tracheal intubation. Children with mild or moderate congenital subglottic stenosis have normal respiratory findings [6]. In children who underwent tracheal intubation for routine surgery, mild and moderate degrees of subglottic stenosis were found in 0.9 and $0.06 \%$ of cases, respectively [7].

Congenital subglottic stenosis is frequently associated with head and neck abnormalities [8-10]. Until now, however, there has been no report of congenital subglottic stenosis diagnosed in patients with first and second branchial arch syndrome. The histopathology of congenital subglottic stenosis includes abnormally shaped cricoid cartilage or laryngeal cleft [11]. Most frequently, the transverse diameter is shorter than normal, making the stenosis detectable on chest X-ray examination [6]. In the present case, detection of the stenosis by preoperative chest X-ray was difficult since the tracheal shape was flattened, while transverse diameter was preserved according to $\mathrm{CT}$ imagery. The narrowest tracheal diameter calculated, based on the CT image, was $3.6 \mathrm{~mm}$ on POD 7. This was much smaller than the average tracheal diameter measured at the subglottic level (for an 11-month-old, 5.0-6.5 $\mathrm{mm}$ in the transverse and $6.0-9.0 \mathrm{~mm}$ for the anteroposterior diameters) [12].

It is sometimes difficult to choose an adequately sized endotracheal tube in children. We chose an ID $4.0 \mathrm{~mm}$ cuffed tube for our first attempt based on the patient's age [13]. In retrospect, this choice was slightly too large when considering recent recommendations [14]. Other predictive protocols, based on height and the fifth fingernail, are also available [15]. While we did not detect air leakage below $30 \mathrm{~cm} \mathrm{H}_{2} \mathrm{O}$ with a 3.0 uncuffed endotracheal tube, we did not consider exchanging it for a smaller tube, since (1) ventilation with a tube size of 2.5 or less would be difficult, owing to increased airway resistance in this patient, (2) the planned (and actual) surgical duration was short, and (3) tube exchange in this condition may have risked inability of re-intubation and mask ventilation. However, placing a tube of this size might have led to exacerbation of congenital stenosis as in newborn cases [16]. Previous reports suggest that detection of an air leak between 10 and $30 \mathrm{~cm}$ $\mathrm{H}_{2} \mathrm{O}$ is indicative of an adequate tube size [17]. Others recommend exchanging the endotracheal tube to a smaller size if it does not leak at $40 \mathrm{~cm} \mathrm{H}_{2} \mathrm{O}$ [13].

According to our literature search, no cases of unrecognized subglottic stenosis reported severe postextubational airway stenosis with [1, 3, 4] or without [2] the prophylactic use of steroids. In contrast, in the present case, symptoms associated with airway stenosis continued for more than $24 \mathrm{~h}$ after surgery and necessitated restarting treatment with dexamethasone. The apparent post-extubation airway stenosis in our case could be attributed to the smaller airway size, as the patient was of a younger age than patients in previous reports.

\section{Conclusions}

We encountered a case of undiagnosed subglottic stenosis that resulted in unexpected difficult tracheal intubation. Airway stenosis continued for $24 \mathrm{~h}$ after the extubation, suggesting the need for careful airway monitoring following extubation.

Availability of data and materials

A copy of data presented in this report is available upon request.

Authors' contributions

NO, FA, SY, YN, YM, TN, and HK performed the patient management. FA and TS wrote the manuscript. All authors read and approved the final manuscript.

Competing interests

The authors declare that they have no competing interests.

Consent for publication

Written informed consent was obtained from the patient's parent for publication of this case report and the accompanying images. 


\section{Author details}

'Department of Anesthesiology, Kyoto Prefectural University of Medicine, Kajii-cho 465 Kamigyo-Ku, Kyoto 604-0096, Japan. ${ }^{2}$ Department of Plastic and Reconstructive Surgery, Kyoto Prefectural University of Medicine, Kajii-cho 465 Kamigyo-Ku, Kyoto 604-0096, Japan.

Received: 8 December 2016 Accepted: 31 January 2017

Published online: 15 February 2017

\section{References}

1. Sato K, Horiguchi T, Nishikawa T. Unsuspected subglottic stenosis in a 5-year-old scheduled for elective surgery. J Clin Anesth. 2005;17:470-2.

2. Kumar KR, Dehran M, Rangasamy V, Govindarajan SR. Unanticipated subglottic stenosis complicating airway management of a child with Langer-Giedion syndrome. Paediatr Anaesth. 2013:23:968-9.

3. Chhibber AK, Hengerer AS, Fickling KB. Unsuspected subglottic stenosis in a two-year-old. Paediatr Anaesth. 1997;7:65-7.

4. Ansari MH, Abraham A. Anaesthetic management of unexpected subglottic stenosis in an achondroplasic dwarf. Acta Anaesthesiol Scand. 2004:48:928-9.

5. Daniel SJ. The upper airway: congenital malformations. Paediatr Respir Rev 2006:7 Suppl 1:S260-263.

6. Rutter MJ. Evaluation and management of upper airway disorders in children. Semin Pediatr Surg. 2006;15:116-23.

7. Mostafa SM. Variation in subglottic size in children. Proc R Soc Med. 1976;69:793-5.

8. Ruan L, Mitchell RB, Pereira KD, Younis RT, Lazar RH. Campomelic syndrome-laryngotracheomalacia treated with single-stage laryngotracheal reconstruction. Int J Pediatr Otorhinolaryngol. 1996;37:277-81.

9. Blanchard M, Leboulanger N, Thierry B, Blancal JP, Glynn F, Denoyelle F, Garabedian EN. Management specificities of congenital laryngeal stenosis: external and endoscopic approaches. Laryngoscope. 2014;124:1013-8.

10. Jacobs IN, Gray RF, Todd NW. Upper airway obstruction in children with Down syndrome. Arch Otolaryngol Head Neck Surg. 1996;122:945-50.

11. Holinger LD. Histopathology of congenital subglottic stenosis. Ann Otol Rhinol Laryngol. 1999;108:101-11.

12. Wani TM, Bissonnette B, Rafiq Malik M, Hayes Jr D, Ramesh AS, Al Sohaibani M, Tobias JD. Age-based analysis of pediatric upper airway dimensions using computed tomography imaging. Pediatr Pulmonol. 2016:51:267-71.

13. Miller RD. Miller's anesthesia. 8th ed. Philadelphia, PA: Churchill Livingstone/ Elsevier; 2015. p. 163088

14. Salgo B, Schmitz A, Henze G, Stutz K, Dullenkopf A, Neff S, Gerber AC, Weiss $M$. Evaluation of a new recommendation for improved cuffed tracheal tube size selection in infants and small children. Acta Anaesthesiol Scand. 2006;50:557-61.

15. Turkistani A, Abdullah KM, Delvi B, Al-Mazroua KA. The 'best fit' endotracheal tube in children — comparison of four formulae. Middle East J Anaesthesiol. 2009;20:383-7.

16. Jefferson ND, Cohen AP, Rutter MJ. Subglottic stenosis. Semin Pediatr Surg 2016;25:138-43

17. Eck JB, De Lisle DG, Phillips-Bute BG, Ginsberg B. Prediction of tracheal tube size in children using multiple variables. Paediatr Anaesth. 2002;12:495-8.

\section{Submit your manuscript to a SpringerOpen ${ }^{\circ}$ journal and benefit from:}

- Convenient online submission

- Rigorous peer review

- Immediate publication on acceptance

Open access: articles freely available online

- High visibility within the field

- Retaining the copyright to your article 